\title{
Shifting Attention From Theory to Practice in Philosophy of Biology
}

\author{
C. Kenneth Waters \\ Minnesota Center for Philosophy \\ Department of Philosophy \\ University of Minnesota
}

\begin{abstract}
Traditional approaches in philosophy of biology focus attention on biological concepts, explanations, and theories, on evidential support and inter-theoretical relations. Newer approaches shift attention from concepts to conceptual practices, from theories to practices of theorizing, and from theoretical reduction to reductive retooling. In this article, I describe the shift from theory-focused to practice-centered philosophy of science and explain how it is leading philosophers to abandon fundamentalist assumptions associated with traditional approaches in philosophy of science and to embrace scientific pluralism. This article comes in three parts, each illustrating the shift from theory-focused to practice-centered epistemology. The first illustration shows how shifting philosophical attention to conceptual practice reveals how molecular biologists succeed in identifying coherent causal strands within systems of bewildering complexity. The second illustration suggests that analyzing how a multiplicity of alternative models function in practice provides an illuminating approach for understanding the nature of theoretical knowledge in evolutionary biology. The third illustration demonstrates how framing reductionism in terms of the reductive retooling of practice offers an informative perspective for understanding why putting DNA at the center of biological research has been incredibly productive throughout much of biology. Each illustration begins by describing how traditional theory-focused philosophical approaches are laden with fundamentalist assumptions and then proceeds to show that shifting attention to practice undermines these assumptions and motivates a philosophy of scientific pluralism.
\end{abstract}

\section{Introduction}

Traditional approaches in philosophy of biology focus attention on biological concepts, explanations, and theories, on evidential support and inter-theoretical relations. Newer approaches shift attention from concepts to conceptual practices, from theories to practices of theorizing, and from theoretical reduction to reductive retooling. They point towards broadening the scope of philosophical attention to investigation, and hence towards analyzing how the integration of practical know-how, concrete knowledge, investigative strategies and theoretical knowledge provides the basis for systematic investigation of the biological world. In this article, I describe the shift from theory-focused to practice-centered philosophy of science and explain how it is leading philosophers to abandon the fundamentalist assumptions associated with traditional approaches in philosophy of science and to embrace scientific pluralism.

This article comes in three parts, each illustrating the shift from theory-focused to practicecentered epistemology. The first illustration concerns conceptual practice in contemporary genetics. I show that geneticists have a flexible concept of the gene that can partition a DNA molecule in a multiplicity of ways. Shifting philosophical attention to conceptual practice reveals

• Minnesota Center for Philosophy of Science \& The Department of Philosophy, 731 Heller Hall, University of Minnesota USA 55455. ckwaters@umn.edu 
how biologists succeed in identifying and manipulating causal strands within systems of bewildering complexity. The second illustration concerns current theorizing about major evolutionary transitions (such as the transition from unicellular to multicellular organisms). This illustration suggests that shifting from the traditional assessment of different theoretical models (in an attempt to identify and articulate the right one) to an analysis of how these models function in practice provides a more illuminating approach for philosophizing about theoretical knowledge in evolutionary biology. The third illustration concerns reductionism. I show how framing reductionism in terms of the reductive retooling of practice, rather than in terms of theoretical or explanatory relations, offers a more informative perspective for understanding why putting DNA at the center of biological research has been incredibly productive throughout much of biology. Each illustration begins by describing how traditional theory-focused philosophical approaches are laden with fundamentalist assumptions and then proceeds to show that shifting attention to practice undermines these assumptions and motivates a philosophy of scientific pluralism.

\section{From concepts to conceptual practices}

Traditional analyses of scientific concepts typically presuppose that the most basic concepts of mature sciences designate the fundamental entities and processes of the respective domains (Bird and Tobin 2012). This presupposition is connected to the idea that parsing nature into its fundamental units is the conceptual basis for comprehensively understanding any domain of nature. This philosophical assumption is often reinforced by scientists' own descriptions of their disciplines. For example, geneticists writing textbooks and on-line glossaries have often written that genes are the "fundamental units of heredity". This implies that the concept of the gene should designate fundamental units in nature, not merely the basic units of a theory. The assumption that science should be based on concepts that designate fundamental units in nature, which is generally shared by philosophers who have examined the gene concept, is a point I contest. But I also argue that the molecular gene concept, correctly understood, is a powerful concept that provides the basis for a very sophisticated conceptual practice. While philosophers of biology are largely skeptical about molecular gene concepts (e.g. Hull 1974, Burian 1986, and Kitcher 1992, and Keller 2000), I am skeptical of the philosophical assumptions that underwrite their skepticism.

The idea that the basic concepts of a science should designate fundamental units in nature naturally leads biologists and philosophers of biology to pose the question, "what is a gene?" What philosophers have found is that biologists do not have a consistent, coherent, and general answer to this question. The most common answer in the biological literature is that a gene is a segment of DNA that codes for a protein. Sometimes this idea is expressed in terms of production: genes are the segments of DNA that produce RNA molecules and RNA molecules are the entities that produce polypeptides. Polypeptide production is important because proteins are comprised of polypeptides, and proteins are very important molecules. They are the building blocks of many biological structures and they play a critical role in the regulation of many important biological processes. The alleged fundamentally of genes is often summarized by the bold assertion that genes direct the development and functioning of organisms by producing proteins. There are a number of problems with such bold assertions, but I will confine my critical attention here to the comparatively modest premise that genes are segments of DNA that produce polypeptides.

Philosophers have criticized this common definition of gene for a number of reasons. Some reasons concern the use of "code for" and "produce". The use of "code for" is especially problematic. Scientists sometimes build on the notion that genes code for proteins by saying that 
the "information" for the protein is contained in DNA. Although the term information is prevalent in molecular biology and genomics, no one has worked out an account of information sufficient for these sciences (Sarkar 1996, Griffiths 2001, Waters 2000, 2008). Furthermore, loose talk about information reinforces the pernicious idea that the information of an organism is coded in its DNA.

The idea that genes are DNA segments that produce RNA molecules that produce proteins is a more promising idea, but it has also been criticized by philosophers. Sometimes this idea is criticized on the ground that the production of polypeptides depends on many kinds of molecules, not just DNA and RNA (Oyama et al 2001). ${ }^{1}$ And, of course, this Millean point is correct. Claiming that DNA is the cause of RNA or protein production, when in fact many different molecules play causal roles in the production of these molecules, is not philosophically defensible. Nevertheless, as I argue elsewhere, DNA does play a distinctive causal role in the synthesis of RNA and RNA plays a distinctive causal role in the syntheses of polypeptides (Waters 2007).

The distinctive roles of DNA and RNA can be explained briefly as follows. Differences among linear sequences of nucleotides within different DNA segments (i.e. within different genes) largely determine differences among the linear sequences of nucleotides within different RNA molecules. In turn, differences among the linear sequences of nucleotides within different RNA molecules largely determine differences among the linear sequences of amino acids within different polypeptides. ${ }^{2}$ So, we can reformulate the gene concept roughly as follows:

genes are segments of DNA that causally determine differences among linear sequences within different polypeptides

I call this the classical molecular gene concept.

This concept of the gene largely escapes parity objections of the Millian variety (because, roughly speaking, genes are the actual difference makers in RNA and polypeptide synthesis while other molecules are not $\left.^{3}\right)$. Nevertheless, the classical molecular gene concept is susceptible to three other criticisms that philosophers have offered against gene concepts: it seems vague, admits exceptions, and is ambiguous. It seems vague because it is unclear where a gene begins and where it ends. Are regulatory units that precede the so-called "coding region" part of the gene or not? Are introns, the DNA segments that correspond to parts of mRNA molecules spliced out before polypeptide synthesis, part of the gene or not? This concept admits exceptions because many DNA segments determine linear sequences in RNA molecules that do not determine linear sequences in polypeptides. For example, rRNA and tRNA are not "transcribed" into polypeptides. So, genes for rRNA and tRNA pose exceptions to this concept of the gene. Finally, the existence of alternative splicing of mRNA gives rise to ambiguities because one DNA segment contains a multiplicity of overlapping segments that determine linear sequences in a set of different polypeptides that result from differential splicing of the same RNA molecule.

What is a gene? Most philosophers weighing in on this issue have concluded that trying to answer this question is hopeless. Evelyn Fox Keller (2000) suggests that the term 'gene' has outlived it

\footnotetext{
${ }^{1}$ The idea that there is parity among genes and other elements takes several subtle forms in philosophical discussions and I will not analyze them here.

${ }^{2}$ I say 'largely' because often in Eukaryotes, differences in other molecules, including splicing agents, also determine actual differences in polypeptides.

${ }^{3}$ See Waters 2007 for a detailed analysis.
} 
usefulness. In apparent frustration, Philip Kitcher (1992) concedes that a gene is anything a competent biologist wants to call a gene. Much of the philosophical literature on this topic implies that the fundamental units of genetics exist at smaller scales (e.g. promoters, enhancers, exons, and introns) or at larger scales (e.g. the level of the gene of classical genetics). Other philosophers have proposed novel gene concepts that seem to depart significantly from conceptual practice. For example, one idea is that genes are processes rather than entities (Griffiths and Neumann-Held 1999). But for the most part, philosophers have decided that the science of today tells us that there is no such thing as a gene at the molecular level.

What about biologists? What do they say when repeatedly pressed by philosophers to answer the question, 'What is a gene? ${ }^{4}$ In my own experience, after being shown that their answers are vague, admit exceptions, or are ambiguous, biologists typically shrug their shoulders. Many quickly concede that they do not know exactly what a gene is. Reflective biologists add that trying to answer the question with the kind of rigor that philosophers demand would be counterproductive. Progress in genetics, they say, has depended and continues to depend on "muddling through". Science, they insist, would be stymied if geneticists were forced to agree on using a clear and unambiguous concept of the gene.

When biologists say "science would be stymied" and that it is better to "muddle through" they have shifted the topic from theory to practice. This suggests that what philosophers should be analyzing are not fixed concepts, but conceptual practice. We should be examining how geneticists are "muddling through". After all, the practice of genetics has been and continues to be spectacularly successful. Philosophers should analyze the reasoning that makes this practice succeed.

A careful analysis of how contemporary geneticists reason when they use the term 'gene' reveals that they use a multiplicity of concepts. Sometimes it is useful to be vague, and in such contexts biologists invoke a blunt concept of the gene from classical genetics, a concept I have called the classical gene concept (see Waters 1994, pp. 165-74, for an analysis of this concept). But in other contexts it is important to be precise. When precision is important biologists employ what I call the molecular gene concept (Waters 1994, 2000).

The molecular gene concept has placeholders. When the placeholders are filled, the concept picks out a precise segment of DNA. So this concept is precise. But it is also flexible because the placeholders can be filled out in a multiplicity of ways, each of which will precisely pick out different segments of DNA. For example when the placeholders are filled out in one way, the concept picks out DNA segments that include introns, when it is filled out in certain other ways it picks out DNA segments that do not include introns. The molecular gene concept is a "gene for" concept and can be articulated as follows:

\footnotetext{
${ }^{4}$ A few biologists have written on this issue and drawn conclusions similar to those of philosophers (e.g. see Portin 1993 and Fogle 2000). Stotz and Griffiths (1994) have put the question 'what is a gene?' to biologists through surveys, keeping track of how biologists in different groups (for example different fields, of different ages, etc.) answer this question. They have explored how biologists answer the question in the context of different kinds of examples. As I read the empirical results, their study indicates that biologists are all over the place. But I have reservations about drawing philosophical conclusions from such studies. See Waters (2004) for a critique of using surveys to analyze scientific concepts.
} 
a gene $\boldsymbol{g}$ for linear sequence $\boldsymbol{l}$ in product $\boldsymbol{p}$ synthesized in cellular context $\boldsymbol{c}$ is a potentially replicating nucleotide sequence, $\mathrm{n}$, usually contained in DNA, that determines the linear sequence $l$ in product $p$ at some stage of DNA expression

The referent of any gene, $g$, is a specific sequence of nucleotides. The exact sequence to which a $g$ refers depends how the placeholders are $l, p$, and $c$ are filled out. As figure 1 illustrates, this provides biologists with the conceptual means to pick out precisely what DNA segments determine different linear sequences in different stages and contexts of DNA expression.

\section{Please insert figure 1 here (provided separately)}

\section{Please use following as caption for figure 1:}

FIG. 1: The molecular gene concept enables biologists to partition DNA in multiple ways. This figure shows how DNA can be partitioned to specify the gene for the primary RNA transcript, and the genes for polypeptides A, B, and C.

The molecular gene concept is a remarkable conceptual tool. It gives biologists the flexibility they need to identify precise causal threads within incredible complexities of DNA expression. It does so by providing the basis for partitioning the DNA molecule in a multiplicity of ways. There is not one, uniquely correct and comprehensive way to divide DNA into genes. There are lots of ways to divide DNA and the molecular gene concept provides the conceptual means for biologist to do so.

The molecular concept of the gene does not divide DNA at it fundamental joints because the molecule has no such joints. Hence, instead of asking 'what is a gene?', with the presumption that genes are units in the uniquely correct partitioning ${ }^{5}$ of DNA, we should be asking 'how should biologists conceive of genes and why? ${ }^{6}$ Answering this question indicates that biologists should conceive of genes in a multiplicity of ways. In some contexts, precision is not important or possible, and biologists conceive of genes in much the same way as classical geneticists did. In other contexts, precision is important. In these contexts biologists should employ the molecular

\footnotetext{
${ }^{5} \mathrm{I}$ am using the term partition in the set theoretical sense of a division into elements that do not overlap.

6 To be more precise, I believe we should be asking two questions: (1) 'what concepts of the gene are at work in successful biological practices? (2) 'what concepts of the gene help us understand the success of biological investigations without inflating the knowledge that makes this success possible?'
} 
gene concept because it provides a flexible and precise way to identify functional units and this enables biologists to slip and slide through the causal complexities of the biological world.

\section{From theories to theoretical practices}

Philosophers view scientific knowledge largely through the central theories and explanations of science. Most work in the philosophy of particular sciences involves analyzing, reconstructing, and extending theories and explanations, and examining how these theories and explanations are or could be justified. The traditional approach is to analyze the central theory of a discipline in order to reveal what is essential for in-principle explanation of everything in the discipline's domain. This approach presupposes that the aim of scientific theorizing is to identify the fundamental relationships (usually presumed to be causal) that are universally responsible for a domain of processes. Philosophical research is often motivated by the assumption that there must be a single right way to formulate the fundamental principles of a mature discipline. The right way to formulate the principles is the one that provides the uniquely correct and comprehensive explanation of the discipline's domain. The traditional philosophical goal is to identify and articulate this single right way.

This approach is well illustrated by work in philosophy of evolutionary biology, which has largely centered on analyzing what philosophers take to be the intellectual core of the scientific discipline: Darwin's theory of natural selection, the theory of population genetics, or more recently the theory of evolutionary genetics based on Price's equation. Philosophers have tried to formulate ideal versions of these theories, and along the way have explored philosophical issues, and scientific ones as well. Elliott's Sober's groundbreaking work, The Nature of Selection (1984), did just that. Sober reconstructed what he took to be the core of evolutionary biology, a theory of population genetics in which natural selection plays the key role, used his reconstruction to frame and explore a number of philosophical issues including ones concerning causation and evidence. He also employed his analysis to address a controversial issue in evolutionary biology about the levels of selection. The approach exemplified in Sober's work continues to dominate philosophy of evolutionary biology. Although philosophers' interest in the levels of selection issue waned as they took up other scientific controversies (such as ones concerning the importance of natural selection and the connection between evolution and development), philosophical research remains theory-focused. Furthermore, and this is a point I wish to stress in this section, philosophers' analyses of evolutionary theory often continues to be framed by the fundamentalist ideal. Although philosophers now disagree about whether the fundamental theory is (or should be) a theory of population genetics, evolutionary genetics based on Price's equation, or a theory that fuses evolution and development, many remain passionately committed to the ideal that there must be one best way to understand evolution, one right way of parsing the causes that divides evolutionary processes into distinct and non-overlapping kinds.

Before proceeding, I should make it clear that I am describing the dominant program of research in the philosophy of evolutionary biology. There are exceptions. Some philosophers are analyzing evolutionary theory from pluralist perspectives (e.g. Waters 1994 and 2005, Sterelny 1996) and some scientists are writing along similar lines (e.g. Dieckmann and Doebeli 2005). Several philosophers, following William Wimsatt's lead (1976, 1980, 1987), have been theory-focused, but have been analyzing practices of theorizing in evolutionary biology without necessarily assuming fundamentalist ideals. In addition, philosophers are beginning to analyze a greater swath of research approaches in evolutionary biology. ${ }^{7}$ I should also stress that there is no

\footnotetext{
${ }^{7}$ For example, a symposium at the most recent Philosophy of Science Association meeting
} 
necessary connection between focusing on theory and adopting fundamentalist ideals. Nevertheless, the dominant program of research in the philosophy of evolutionary theory is not only to analyze the products of theoretical practices, but also to analyze them from a monistic perspective with the goal of identifying and articulating the uniquely correct and comprehensive basis for parsing and explaining all evolutionary phenomena. ${ }^{8}$ This is what I mean when I use the term traditional theory-focused approach.

One scientific issue that has recently come to the forefront of philosophers' attention concerns major evolutionary transitions, such as the transition from prokaryotes to eukaryotes and the transition from unicellular organisms to multicellular organisms. How evolution proceeds through such transitions has drawn increasing attention among evolutionary biologists over the past few decades. A central theoretical idea is that these transitions involved groups of organisms evolving into individuals. For example, biologists theorize that multicellular organisms have evolved from groups of conspecific single-celled organisms. How did this evolution proceed? Evolutionary biologists are pursuing a number of different approaches to answer this question including experimental (e.g. Ratcliff et al 2012), historical/comparative (e.g. Herron and Michod 2007), informal theorizing (e.g. Kirk 2005), and highly abstract mathematical theorizing (see below). Philosophical attention, of course, has gravitated towards analyzing the most abstract theorizing on this issue because this is the approach that presumably gets at the fundamentals.

Much of the abstract theorizing about the evolution of multi-cellularity centers on the idea that cooperation among single-celled organisms in groups evolved by natural selection until the groups exhibited the characteristics of multicellular individuals. Theoretical biologists are employing abstract models of multilevel selection to represent how this process proceeded. By happy coincidence (perhaps), philosophers have already analyzed multilevel selection theory and reconstructed two different kinds of multilevel selection (Mayo and Gilinsky 1987, and Damuth and Heisler 1988). These kinds or model-types have been called MLS1 and MLS2 (multi-level selection types 1 and 2). The fact that biologists equivocate between these different models raises interesting philosophical questions for the fundamentalist philosopher. What is multilevel selection, is it MLS1 or MLS2? Or maybe multilevel selection comes in two forms? Perhaps some processes of multilevel selection take one form, correctly modeled by MLS1, and other processes of multilevel selection take the other form, correctly modeled by MLS2. But if this is the case, then there must be a more fundamental theory that subsumes both model-types. What is this theory? The philosopher (i.e. the fundamentalist philosopher) wants to know.

These questions have been taken up by Samir Okasha (2006), who has concluded that MLS1 and MLS2 model-types identify different kinds of evolutionary processes, both of which are subsumed under Price's equation. ${ }^{9}$ Okasha's analysis of biologists' theorizing about how evolution proceeds through the transition to multicellularity leads him to conclude that the transition involves successive processes, and that one model-type (MLS1) accounts for early

examined experimental modeling in evolutionary biology (Waters et al, 2012).

${ }^{8}$ Consider, for example, the two most recent books in philosophy of biology to win the Lakatos Award, Okasha (2006) and Godfrey-Smith (2009). Both books adopt what I call a fundamentalist perspective.

${ }^{9}$ Okasha claims that "unlike most formal descriptions of the evolutionary process, it [Price's equation] rests on no contingent biological assumptions, so always holds true" (p. 19). He also claims that the Price formalism "subsumes all more specific models as special cases" (p. 3). But he contradicts this latter claim later in his book, and there is good reason to think that the kind of toolbox theorizing I am advocating with respect to model types MLS1 and MLS2 applies at the level of the Price equation and its formal rivals such as contextual analysis (see Waters 2010). 
processes (or "stages) in the evolutionary transition and the other model-type (MLS2) accounts for later processes (or "stages"). If we adopt the fundamentalist perspective of traditional theoryfocused philosophy of science, as Okasha does, we would assume that these model-types represent distinct kinds of causal processes. On this view, for any particular process of multi-level selection, either an MLS1 model or an MLS2 model, but not both, provides the correct causal account. We might say of one token process, 'this is MLS1' and of another 'this is MLS2'. We would not, however, say of one process that it is both MLS1 and MLS2.

This analysis, however, raises a difficult question. Given that the evolution from unicellular organisms to multicellular individuals was continuous, how did the evolutionary processes transition from being MLS1 to being MLS2? By leap, or by gradual transition? Were intermediate stages both MLS1 and MLS2? The strict fundamentalist has to say no. MLS1 and MLS2 are distinct kinds. Any single process must belong to at most one of these kinds. Okasha suggests that the evolutionary transition to multicellularity involved intermediate stages in which MLS1 and MLS2 processes were separately occurring (Okasha 2006, p. 59) But he offers no analysis of how this is possible, and no argument why this must be so. It seems to be a conclusion reached on pure faith in the ideal that complex transitions must neatly decompose into processes falling into distinct kinds for which there are in-principle explanations grounded in fundamental principles.

There is another philosophical approach. If we center our attention on the practice of theorizing (instead of trying to interpret, in fundamental terms, the theories that emerge from that practice), what we observe is that evolutionary theorists employ different model-types, and one model-type (MLS1) is better suited to describing causation in the early stages of the evolution of multicellularity, and the other model-type (MLS2) is better suited to describing causation in later stages. Perhaps the middle stages are so messy that neither model-type can be used to describe the causation cleanly. Perhaps, as in the case of molecular biology described in section 1, these evolutionary processes are so incredibly complex that there is no universally applicable parsing of the causes. Why should we believe evolutionary processes must fall neatly into distinctive kinds of processes, that each of these kinds of processes can be fully represented by one model-type, and that the collection of model-types explaining the different kinds of processes can be subsumed under a single set of fundamental principles?

If evolutionary processes do not fall into distinctive kinds, then theorizing as if they did, might be counterproductive in the same way as insisting upon a single rigid concept of gene would be counter-productive in genetics. Theoretical evolutionary biologists need to slip and slide through the complexities of evolutionary history just as molecular biologists need to slip and slide through the complexities in their domains of investigation. The philosophical task, I submit, is to analyze how theoreticians succeed to make sense out of the complexities.

I began this section by describing the fundamentalist view embedded in the traditional approach to analyzing scientific theories. Of course, philosophy, like biology, is pluralistic and there is no necessary connection between focusing on theoretical products and holding the fundamentalist view. ${ }^{10}$ For example, philosophers of biology interested in systematics, which is an important part of evolutionary biology, have developed accounts of natural kinds that are more suited to represent the blurring and merging of kinds (e.g. Dupré 1981, Ereshefsky 1998). But it is unclear how accounts, such as Boyd's homeostatic cluster account of natural kinds (1999), could be

${ }^{10}$ I thank Marc Ereshefsky for reminding me that theory-focused philosophers of biology have done a good job critiquing the fundamentalist conception of natural kinds and that they have developed promising alternatives for understanding kinds of entities. 
applied to processes. In any case, when philosophers analyze the basic theories of evolution, the analyses typically presuppose old-fashioned ideas about natural kinds of processes, fundamental principles, and universal in-principle explanation.

It is appropriate to conclude this section by drawing an explicit contrast between the perspective of theorizing presupposed by the traditional theory-focused approach and the view that emerges from centering philosophical attention on the practice of theorizing.

Fundamentalist view presupposed by the traditional analysis of theories: the aim of scientific theorizing is to identify the fundamental causal relationships that are universally responsible for a domain of processes. Achieving this aim entails articulating the fundamental theoretical concepts and causal principles that can provide a basis for constructing models that decompose the causes of each and every process in the uniquely correct way. Proponents of this view stress the idea that there is, of course, just one way the world actually is, and the aim of theorizing is to describe, in a principled manner, the one way it actually is.

Toolbox view ${ }^{11}$ that emerges from centering philosophical attention on practices of theorizing: one aim of scientific theorizing is to construct causal models that explain aspects of the processes in a domain. Achieving this aim entails articulating a multiplicity of theoretical concepts and causal principles that can be drawn upon to construct models that might decompose the causes of different processes in different ways and the causes of some processes in a multiplicity of ways. In cases of multiplicity, some concepts and models offer the best account of some aspects of a given process, other concepts and models provide the best account of other aspects.

The toolbox view does not deny that the world is one way. But it rejects the assumption that there must be one best way to describe the world, and that this one best way offers a principled, unified, and comprehensive basis for explaining every aspect of the world. On the toolbox view, part of the work of philosophy is to formulate ideal accounts of how scientists should theorize in such a world. To achieve this, philosophers should analyze practices of scientific theorizing, especially those involving complex phenomena such as evolution.

\section{From theory reduction to reductive retooling of practices}

Accounts of reductionism in philosophy of science focus on theoretical and explanatory relations. The basic idea, which was set out in canonical form by Ernest Nagel (1961), is that the core principles of a reduced theory are derived (or explained) by core principles of a reducing theory. ${ }^{12}$ Nagel combined this formal idea with a historical one: scientists first establish a "higher-level" theory, and afterwards reduce it by deriving its principles from a "lower-level" theory. The higher-level theory is revised in the process of being reduced, and the revision provides more accurate explanations and predictions over a greater range of phenomena. Hence, theoretical

\footnotetext{
${ }^{11}$ Maxwell (manuscript), Cartwright et al, (1995), Cartwright (1999), Suårez and Cartwright (2008) and Wimsatt (2007) offer ideas about theorizing similar to the one I am advancing here and also use the 'toolbox' term and metaphor.

${ }^{12}$ Some recent accounts of reduction frame reduction in different ways, but still with the emphasis on theoretical and/or explanatory relations. For example, Hüttemann and Love (2011) couch it in terms of explanations in which an outcome described at a higher level (explandum) is explained by earlier states described at lower level(s). This article illustrates that focusing on the theories and explanations does not necessarily presuppose fundamentalism, and that paying attention to theoretical and explanatory practices undermines the fundamentalist ideals.
} 
reduction purportedly advances science towards integrated, monistic, and comprehensive knowledge.

Kenneth Schaffner (1969) applied Nagel's model to biology and claimed that the theory of classical genetics was being reduced to a theory of molecular genetics. Schaffner's claim has been roundly rejected by philosophers of biology (Hull 1974, Wimsatt 1976, Darden and Maul 1977, Hooker 1981, Kitcher 1984, and Rosenberg 1985). Yet few critics would now deny that the discipline of genetics has in some sense gone molecular and that the molecularization of genetics has led to a dramatic transformation of much of biology. Questions about how the molecularization of genetics transformed the biological sciences, however, have fallen through the cracks of philosophical inquiry.

Critics of Schaffner's account have typically abandoned reductionism, but not his focus on theories and theoretical explanations. From the traditional theory-focused perspective, the lack of impressive reductive explanations (or derivations) of the central principles of classical genetics suggests that there is nothing more to say about the reduction of genetics. ${ }^{13}$ But if we stop focusing exclusively on theoretical developments and broaden our attention to the investigative practice of classical genetics, an impressive reductive retooling of this practice becomes visible. The reductive retooling of classical genetics is the source of the dramatic transformation of much of biology into DNA-centered science. ${ }^{14}$ In many biological sciences, it is the investigative strategies and procedures, not the explanations, that center on DNA.

Traditional conceptions of theoretical reduction assume that the aim of science is to provide a unified and comprehensive, theoretical explanation of the world, an explanation based on fundamental principles (or laws). This view, as exemplified in Nagel's model of theoretical reduction, takes the structure of scientific knowledge to resemble the structure of a layer cake. Each layer of science (physics, chemistry, biochemistry, genetics, . . .) searches for the principles that are essential for explaining everything at the level of its domain. Reductionists claim that the principles at higher levels of the cake are "reducible" to principles at lower levels. In Nagel's version of reductionism, this means that the principles at higher levels are derivable from principles at lower levels. Antireductionists generally accept the basic layer cake picture of scientific knowledge. But they disagree with reductionists about how successive layers of the cake relate to one another. Antireductionists argue that the principles essential for explaining domains of phenomena at higher levels are not reducible to lower-level principles. ${ }^{15}$

Reductionists and antireductionists also share a common epistemic ideal about knowledge within each layer of scientific knowledge. ${ }^{16}$ According to this ideal, scientists seek to discover and establish the uniquely correct theory that provides an in-principle explanation of everything in a domain. Investigation in mature sciences is successful according to this ideal because the core

${ }^{13}$ Kitcher (1984) offers an alternative, theory-focused, non-reductive account of how molecular genetics contributes to the science of genetics. But Hull (1974) implied that there was something reductive happening in genetics, but that what was happening did not fit Nagel's model.

${ }^{14}$ Many of the points in this section are developed in more detail in Waters 2008a.

${ }^{15}$ Not all reductionists accept the layer-cake image (e.g., Weber 2005), and some antireductionists seem more interested in advancing holism than multileveled holism (e.g., various contributors to Oyama et al. 2001). Nevertheless, many philosophers cling to the idea that biology is organized into separate sciences, each of which is focused on a particular level of organization.

${ }^{16}$ This epistemology is generally presupposed even by reductionists and antireductionists who reject the layer-cake image (e.g. Weber 2005, Oyama et al. 2001). 
theories get the fundamentals basically correct and this provides the basis for explaining a greater range of phenomena with increasing accuracy.

The theory-focused view of theoretical reductionism can be summarized as follows.

Reductionism contributes to the advance of a science by connecting theories at higher levels, which have relatively narrow domains, to theories at lower levels, whose domains are broader. In doing so, the reduced theories are improved upon and provide better bases for explaining a greater range of phenomena within their domains. This view offers an account of why reduction is fruitful, the feature of reduction which Nagel himself claimed was most important. Reduction is fruitful, on this account, because it improves theory, and improving theory is what inquiry is all about!

Practice-centered epistemology leads to a different account of why reductionism is fruitful. The practice-centered view does not assume that science has any single aim such as improving theory. ${ }^{17}$ Science is practiced by scientists with a multiplicity of aims. Among the commonly shared aims are the quests to investigate, manipulate, and explain phenomena. In mature sciences, such as classical genetics (by the mid1920s), scientists have the means to investigate systematically a domain of phenomena. But this is not necessarily because they have a core theory that provides an in-principle explanation of everything in the domain. That is, the success of their practice does not rest on a core theory that grasps the fundamentals.

The core theories of sciences like classical genetics, explain very little, even in-principle, with respect to the domains being systematically investigated. But in addition to core theories, scientists have concrete knowledge, procedural know-how, and strategic approaches that enable them to investigate ranges of phenomena that far outstrip the ranges of phenomena that their core theories can possibly explain. What provides the bases for systematic investigation are not the core theories by themselves, but the investigative matrices into which these theories are assimilated. ${ }^{18}$

In the case of classical genetics, the core theory was the transmission theory of genetics. All it could explain, in-principle, was the transmission of phenotypic differences from one generation to the next. But it played an important role in the strategic approach that classical geneticists used to investigate a wide variety of basic processes. Their approach, "the genetic approach", was to (a) identify naturally occurring or artificially produced mutants that exhibit a difference relevant to some biological process of interest, (b) carry out genetic analyses of the mutants, and (c) recombine the mutants to learn more about the process of interest. Theory was integral to carrying out each of these steps, but doing so was also depended on concrete knowledge, procedural know-how, and strategic approaches. What is critical for understanding the power of genetics is what has been completely overlooked in the uniformly theory-focused accounts of classical genetics contained in the philosophical literature. Namely, the core strategy of the genetic approach: classical geneticists sought to use mutations as tools to disrupt the processes they wished to investigate, and in disrupting the processes they sought to learn about how the processes worked.

\footnotetext{
${ }^{17}$ Debates in philosophy of science are sometimes framed as disagreements about "the aim" of science. For example, van Fraassen (1980) characterizes his disagreement with scientific realists as centering on the aim of science. I reject the idea that there is something called "science" that has a single aim.

${ }^{18}$ See Waters $2004 \mathrm{~b}$ for an elaboration of this account.
} 
The basic strategy of learning about biological processes by disrupting them wasn't new. For centuries, physiologists investigated mechanisms, such as the mammalian circulatory system, by interfering with its parts and observing what happens when the processes are subsequently disrupted. In fact, amateur mechanics use this investigative approach to investigate how machines work. What was new to classical genetics was the idea that one could disrupt processes, such as sex determination, by recombining genetic mutations.

The genetic approach had mixed success in classical genetics. It tended to be most successful in the study of chromosomal mechanics. But the approach was not confined to investigating chromosomal processes. It was also used to learn about basic biological processes such as gene action, mutation, development, and evolution. For example, mutants involving dosage effects and genetic mosaics were often investigated in order to shed light on gene action or on broader issues of development, such as sex determination. Generally, this research did not live up to the promise of yielding important new knowledge about the basic processes being investigated (at least in the short run). But as Robert Kohler (1994) observed, even when experiments did not lead to new knowledge about the phenomena being investigated (such as sex determination), they still yielded publishable information about the existence and genetic location of new alleles. This helps explain why the underlying investigative strategy that systematized research in classical has subsequently disappeared from view, and why it appears from hindsight that the point of the experimentation was to discover and map new genes.

The epistemology of scientific practice exemplified by classical genetics can be summarized as follows. Investigative practice has two domains. One range, the explanatory range of its core theory, is the domain of what can be explained, at least in principle, by its core theory. The other, which I call the investigative reach, is what can be systematically investigated and explained in piecemeal fashion by employing the investigative matrix, which consists of an assimilation of core theory, concrete knowledge, procedural know-how, and strategic approaches. Classical genetics illustrates how the explanatory range of a core theory is much narrower than the investigative reach of the investigative practice. The core theory in this case, the transmission theory, could explain only the transmission of phenotypic differences from one generation to the next. But the genetic approach drew upon this theory, concrete knowledge, and procedural knowhow in an effort to systematically investigate a broad range of basic biological processes. If successful, these efforts yield piecemeal explanations of parts and aspects of processes outside the explanatory range of the core theory. In the case of classical genetics, however, these efforts rarely yielded such explanations.

With this practice-centered understanding of classical genetics in place, we can answer questions about what the molecularization of genetics consisted of, how it turned genetics into such powerful science, and how genetics subsequently transformed much of biology. In brief, molecularization of genetics consisted of a retooling of investigative practice. When mutations were identified with physical differences in DNA, they could be screened, isolated, moved, and tracked with remarkable precision. Geneticists learned how to engineer new mutations. These procedural gains make it possible to deftly manipulate all kinds of biological processes, and this has greatly enhanced the power of the genetic approach of investigation. This power is being wielded by investigators throughout the biological sciences. This is what has transformed biology.

A typical example of DNA-centered research in neuroscience illustrates how the genetic approach systematizes research without being guided by a core theory (i.e. without being guided by a theory that alleged offers an in-principle explanation of the process being investigated). Among the processes investigated in neuroscience is the formation of neurological systems during the 
development of individual organisms. Investigation often takes the form of identifying the functional role of various elements in particular processes or mechanisms of development.

For example, Bastian, Jorgensen, and Hammarlund at the University of Utah have investigated the establishment of neural connections between the ventral and dorsal nerve chords in the nematode, C. elegans (Hammarlund et al 2007). ${ }^{19}$ Investigators had already discovered that a protein, $\beta$-spectrin, is located in the growth cones of nerve cells that are growing from the ventral to dorsal nerve chords. This discovery led to the hypothesis that $\beta$-spectrin plays a functional role in the growth of these neurons (as they are forming the connection between ventral and dorsal nerve chords). But Bastian, Jorgensen, and Hammarlund learned that the role of $\beta$-spectrin is to protect the delicate neuronal structure that connects the nerve chords from acute strains. That is, they learned, that $\beta$-spectrin serves its role after the connection is made, and apparently not before. They learned this by using the genetic approach.

Bastian, Jorgensen, and Hammarlund disrupted the developmental processes they were investigating by manipulating genes. They made the processes visible by inserting a gene for green fluorescent protein (GFP). Obviously this gene did not play a role in the explanation of neuronal growth or maintenance. In the first stage of their investigation, the researchers prevented $\beta$-spectrin from being synthesized in experimental organisms by using a mutated version of the gene for $\beta$-spectrin. They learned that the neurons developed normally, which suggested that the role of of $\beta$-spectrin is to prevent degeneration of the neuronal extensions, not facilitate their growth. ${ }^{20}$

In the next stage of experimentation, the investigators immobilized worms by interfering with the expression of the gene for mysosin. They observed that the neurons of immobilized worms lacking $\beta$-spectrin maintained their structure about as well as worms with $\beta$-spectrin. These results were checked by manipulating a fourth gene, twitchen, which did not immobilize the worms but did prevent them from moving in ways that would exert acute strains on the relevant nerve cells extensions. They observed that the neuronal connections in twitchen worms lacking $\beta-$ spectrin were maintained about as well as the neurons as worms with $\beta$-spectrin. The combination of results indicated that the functional role of $\beta$-spectrin is to protect neurons against acute strains.

Bastian, Jorgensen, and Hammarlund's explanation about the function of $\beta$-spectrin is appropriately couched in terms of proteins and cytoskeletal structures, not in terms of genes or DNA. These neuroscientists intervened on genes and DNA expression to manipulate the processes they were investigating, but genes and DNA were not part of the mechanistic explanation that emerged from their research. The point worth emphasizing is that their research was not guided by an attempt to fill out the details of a gene-centered theory. This example illustrates how investigation can be systematized by the genetic approach, an investigative strategy, without being guided by a comprehensive gene-centered theory about the phenomena to be explained.

The difference between the conception of reduction that emerges by centering attention on investigative practice instead of focusing on theory and explanation can be summarized with three contrasts. First, whereas the theory-focused conception of reduction holds that core

${ }^{19}$ As in the case of classical genetics (see Waters 2004b), investigators carry out their work on model organisms that have been adapted for laboratory practice.

${ }^{20}$ Given the possibility of redundant pathways to the development of the neurons, the results did not prove that $\beta$-spectrin has no role in the growth if these neuronal extensions, but the results did show that the role was not essential. 
principles of the reduced theory are derived (or explained) by core principles of a reducing theory, the practice-centered conception holds that elements of an investigative practice are associated with elements at smaller scales. For example, in the retooling of genetics, mutations in genes on chromosomes are associated with differences in linear sequences in DNA (see Weber 2005, pp. 157-69). Second, whereas focusing on theory assumes the power of reduction must be an increase in explanatory power of a reduced theory, centering attention on practice reveals that the power of reduction stems from an increase in the power to manipulate and hence investigate a greater range of processes. Retooling increased the power of genetics because it enabled biologists to manipulate and track a wide range of processes by intervening on DNA. Third, embedded within the theory-focused view of reduction is the assumption that the role of reduction is to advance science towards an integrated, monistic, and comprehensive understanding of the world. According to the practice-centered view, reductive retooling advances science towards more powerful means of control and a fragmentary understanding of a greater number of aspects and parts of the world.

\section{Conclusion}

Philosophy of science is, as Ian Hacking (1983) remarked, theory-biased. The bias often involves not just focusing attention on theories and explanations, but also on using an approach that presupposes a metaphysics and epistemology of fundamentalism. Such bias leads to a distorted understanding of scientific knowledge and practice, one that attributes the success of a mature science to its core theory providing an in-principle, comprehensive explanation of everything in the science's domain.

Theory-bias obscures the most remarkable feature of science: scientists' ability to manipulate, explain, and predict aspects of and parts of a world when they lack the kind of understanding that many philosophers assume they must have (or approximate) in order to be successful. What scientific success actually consists of, how scientists achieve this success, and how we should interpret the results of their success are what I take to be central questions for philosophy of science. The best way to approach these questions is to broaden our attention to the practice of science and to free ourselves from the fundamentalist assumptions that have restricted traditional philosophical inquiry. 


\section{References}

Bird, A. and Tobin, E. (2012) "Natural Kinds", in: E. N. Zalta, ed. The Stanford Encyclopedia of Philosophy (Winter 2012 Edition). http://plato.stanford.edu/archives/win2012/entries/naturalkinds/.

Boyd, R. (1999) "Homeostasis, Species, and Higher Taxa”, in: R. Wilson (ed.), Species: New Interdisciplinary Essays, Cambridge, Massachusetts: MIT Press, p141-186.

Burian, R. M. (1986) "On Conceptual Change in Biology: The Case of the Gene", in: D. J. Depew and B. H. Weber, eds. Evolution at a Crossroads. Cambridge, MA: MIT Press, pp. $21-42$.

Cartwright, N. D. (1999) The Dappled World: A Study of the Boundaries of Science. Cambridge: Cambridge University Press.

Cartwright, N., Shomar, T. and Suárez, M. (1995) "The Tool Box of Science”, in: W. Herfel, W. Krajewski, I. Niiniluoto and R. Wojcicki, eds. Theories and Models in Scientific Processes Amsterdam: Rodopi, pp. 137-149.

Damuth, J. and Heisler, I. L. (1988) “Alternative Formulations of Multi-level Selection”, Biology and Philosophy 3: 407-430.

Darden, L. and Maul, N. (1977) "Interfield Theories", Philosophy of Science 44: 43-64.

Dieckmann, U. and Doebeli, M. (2005) "Pluralism in Evolutionary Theory", Journal of Evolutionary Biology 18(5): 1209-1213.

Dupré, J. (1981) "Natural kinds and biological taxa", The Philosophical Review 90: 66--90.

Ereshefsky, M. (1998) "Species Pluralism and Anti-Realism", Philosophy of Science 65:103-120.

Fogle, T. (2000) "The Dissolution of Protein Coding Genes in Molecular Biology", in: P. Beurton, R. Falk and H-J. Rheinberger, eds. The Concept of the Gene in Development and Evolution. Historical and Epistemological Perspectives. Cambridge: Cambridge University Press, pp. 3-25.

Giere, R. (1988) Explaining Science: A Cognitive Approach. Chicago: University of Chicago Press.

Godfrey-Smith, P. (2009) Darwinian Populations and Natural Selection. Oxford: Oxford University Press.

Griffiths, P. E. (2001) "Genetic Information: A Metaphor in Search of a Theory", Philosophy of Science 68(3): 394-412.

Griffiths, P. E. and Neumann-Held, E. M. (1999) “The Many Faces of the Gene”, BioScience 49(8): 656-662.

Hacking, I, (1983) Representing and Intervening. Cambridge: Cambridge University Press.

Hammarlund, M., Jorgensen, E. M. and Bastiani, M. J. (2007) “Axons Break in Animals Lacking ß-Spectrin.” Journal of Cell Biology 176(3): 269-275.

Herron, M. D. and Michod, R. E. (2007) "Evolution of Complexity in the Volvocine Algae: Transitions in Individuality Through Darwin's Eye”, Evolution 62(2): 436-451.

Hooker, C. A. (1981) "Towards a General Theory of Reduction. Part I: Historical and Scientific Setting, Part II: Identity in Reduction, Part III: Cross-categorical Reduction”, Dialogue 20: 38-59, 201-236, 496-521.

Hull, D. L. (1974) The Philosophy of Biological Science. Englewood Cliffs, NJ: Prentice-Hall.

Hüttemann, A. and Love, A. C. (2011) "Aspects of Reductive Explanation in Biological Science: Intrinsicality, Fundamentality, and Temporality", British Journal for Philosophy of Science 62: 519-549.

Keller, E. F. (2000) Century of the Gene. Cambridge: Harvard University Press

Kirk, D. L. (2005) "A Twelve-step Program for Evolving Multicellularity and a Division of Labor", BioEssays 27: 299-310.

Kitcher, P. S. (1992) "Gene: Current Usages", in: E. Keller and L. Lloyd, eds. Keywords in Evolutionary Biology. Cambridge, MA: Harvard University Press, pp. 128-131. 
Kohler, R. E. (1994) Lords of the Fly: Drosophila Genetics and the Experimental Life. Chicago: University of Chicago Press.

Maxwell, G. (manuscript) “Toolbox Theorizing” Minnesota Center for Philosophy of Science Maxwell Archive.

Mayo, D. G. and Gilinsky, N. L. (1987) “Models of Group Selection”, Philosophy of Science 54(4): 515-538.

Maul, N. (1977) "Unifying Science without Reduction", Philosophy of Science 8: 43-71.

Nagel, E. (1961) The Structure of Science: Problems in the Logic of Scientific Explanation. New York, N.Y.: Harcourt, Brace \& World.

Okasha, S. (2006) Evolution and the Levels of Selection. Oxford: Oxford University Press.

Oyama, S., Griffiths, P. E. and Gray, R. D. (2001) "Introduction: What is Developmental Systems Theory?”, in: S. Oyama, P. E. Griffiths, and R. D. Gray, eds. Cycles of Contingency, Cambridge, MA: Bradford/MIT Press, pp. 1-12.

Portin, P. (1993) "The Concept of the Gene: Short History and Present Status" The Quarterly Review of Biology 68: 173-223.

Ratcliff, W. C., Denison, R. F. Borrello, M. and Travisano M., (2012) "Experimental Evolution of Multicellularity", Proceedings of the National Academy of Science 109(5): 1595-1600.

Rosenberg, A. (1985) The Structure of Biological Science. Cambridge: Cambridge University Press.

Sarkar, S. (1996) "Biological Information: A Skeptical Look at Some Central Dogmas of Molecular Biology", in: S. Sarkar, ed. The Philosophy and History of Molecular Biology: New Perspectives. Dordrecht: Kluwer, pp. 187-231.

Schaffner, K. (1969) "The Watson-Crick Model and Reductionism", British Journal for the Philosophy of Science 20: 235-248.

Sober, E. (1984) The Nature of Selection: Evolutionary Theory in Focus. Cambridge, MA: Bradford/MIT Press.

Sterelny, K. (1996) "Explanatory Pluralism in Evolutionary Biology", Biology and Philosophy 11(2): 193-214.

Stotz, K., Griffiths, P. E. and Knight, R.D. (2004) "How Scientists Conceptualise Genes: An Empirical Study", Studies in History \& Philosophy of Biological and Biomedical Sciences 35(4): 647-673.

Suárez, M. and Cartwright, N. (2008) "Theories: Tools Versus Models", Studies in History and Philosophy of Modern Physics 39: 62-81.

van Fraassen, B. (1980) The Scientific Image, Oxford: Oxford University Press.

Waters, C. K. (1994) “Tempered Realism about the Force of Selection”, Philosophy of Science 58: 553-573.

(1994) “Genes Made Molecular", Philosophy of Science 61: 163-185. (2000) “Molecules Made Biological”, Revue Internationale de Philosophie 54(214): 539_ 564.

(2004a) "What Concept Analysis Should Be", History and Philosophy of the Life Science 26: $29-58$.

_ (2004b) "What was Classical Genetics?", Studies in History and Philosophy of Science 35: 783-809.

(2005) "Why Genic and Multilevel Selection Theories are Here to Stay", Philosophy of Science 72(2): 311-333.

— (2008a) "Beyond Theoretical Reduction and Layer-cake Antireduction: How DNA Retooled Genetics and Transformed Biological Practice", in: M. Ruse ed. Oxford Handbook to the Philosophy of Biology. New York, NY: Oxford University Press, pp. 238-262. (2008b) "Molecular Genetics", The Stanford Encyclopedia of Philosophy (Fall 2013 Edition), E. N. Zalta ed. forthcoming http://plato.stanford.edu/archives/fall2013/entries/molecular-genetics/. 
_ (2010) “Okasha's Unintended Argument for Toolbox Theorizing”, Philosophy and Phenomenological Research 82(1): 232-240. [pre-print of unabridged version on PhilSciArchive.pitt.edu]

Waters, C. K., Hillesland, K. Weber, M. and Travisano, M. (delivered in 2012) "Can Experimental Modeling Play the Role of Theorizing in Evolutionary Biology?", Philosophy of Science Association 2012 Biennial Meeting, San Diego, CA.

Weber, M. (2005) Philosophy of Experimental Biology. Cambridge: Cambridge University Press.

Wimsatt, W. (1976) "Reductive Explanation: A Functional Account", in: R. S. Cohen, C. A. Hooker, A. C. Michalos and J. W. Van Evra, eds. PSA 1974 Proceedings of the 1974 Biennial Meeting Philosophy of Science Association (Boston Studies in the Philosophy of Science, volume 32) Dordrecht: Reidel, pp. 671-710. (1980) "Reductionistic Research Strategies and their Biases in the Units of Selection Controversy", in T. Nickles, ed. Scientific Discovery: Case Studies. (Boston Studies in the Philosophy of Science, volume 60) Dordrecht: Reidel, pp. 213-259.

(1987) "False Models as Means to Truer Theories", in: M. Nitecki and A. Hoffman, eds. Neutral Models in Biology, London: Oxford University Press, pp. 23-55. (2007) Re-Engineering Philosophy for Limited Beings: Piecewise Approximations to Reality. Cambridge: Harvard University Press. 